\title{
The role of leadership in shaping organisational climate: An example from the fast moving consumer goods industry
}

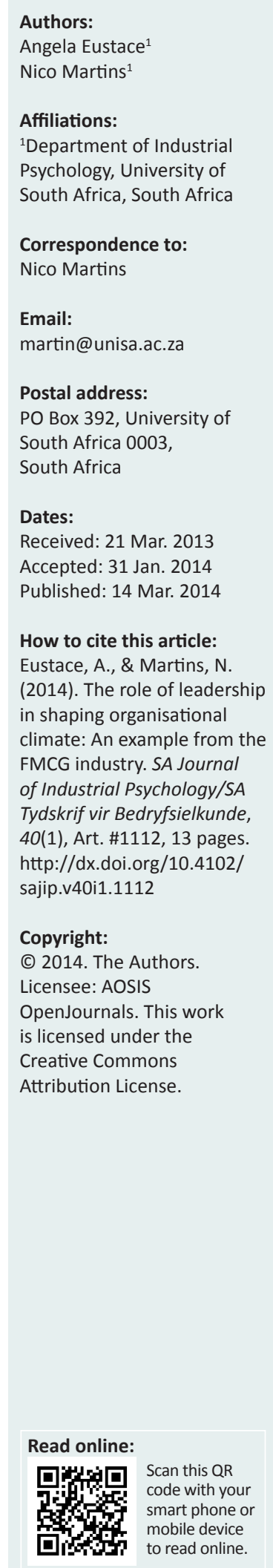

Orientation: The 21st century has presented challenges and opportunities to organisations. Although South Africa is the most competitive economy in sub-Saharan Africa, the country needs to focus on these opportunities to improve competitiveness. Although there is research on leadership and organisational climate, a debate continues about the contribution of organisational climate and the role of leadership to creating the desired organisational climate.

Research purpose: The aim was to explore the relationship between leadership and organisational climate in a South African fast moving consumer goods (FMCG) organisation.

Motivation for the study: Few studies focus on leadership and organisational climate in South Africa. This study builds on the knowledge that exists. An understanding of the effect of leadership on organisational climate in South Africa allows for customised solutions to the problems of leadership, organisational climate and business performance.

Research design, approach and method: Using a descriptive, cross-sectional field survey approach, 896 participants (all of whom worked in one organisation) participated in the survey.

Main findings: An exploratory factor analysis (EFA) and structural equation modelling (SEM) multivariate analyses revealed a new set of organisational dimensions, confirmed the relationship between leadership and organisational climate as well as the relationship between organisational climate and its various dimensions.

Practical/managerial implications: The findings emphasised the importance of certain generic and specific leadership practices for creating the desired organisational climate in South Africa and in the FMCG environment.

Contribution/value-add: This study contributes to the body of knowledge about the relationship between leadership and organisational climate in South Africa.

\section{Introduction}

\section{Key focus of the study}

Today's changing technological landscape presents organisations, leaders and employees with a multitude of challenges and opportunities. Increasing volatility and turbulence characterise the business world. According to the 2012 International Labour Organization (ILO) Report on global employment trends, the world faces the 'urgent challenge' of creating 600 million productive jobs within the next 10 years in order to generate and achieve sustainable growth and preserve social cohesion (see ILO [n.d.]). In addition, The Global Competitiveness Report 20112012 showed that South Africa ranked fourth (of 144 countries surveyed) in financial market development. This shows confidence in the South African market, whereas confidence is only slowly returning to other countries across the globe. The report also showed that South Africa performs relatively well in complex areas like business sophistication (38th), innovation (41st), benefiting from sound scientific research institutions (30th) and strong collaboration between universities and the business sector in innovation (26th).

However, South Africa needs to address a number of weaknesses. They include poor labour market efficiency, which rigid hiring and termination of employment practices (139th) characterise, the inflexibility of organisations in determining compensation (138th) and significant tensions in employee-employer relationships (138th). All these problems require strong leadership and high quality relationships between employees and leaders so that they can work together to find appropriate solutions.

Therefore, it is essential to improve leadership and the organisational climate that is necessary for improved productivity, market share growth and profitability. This is important, given 
South Africa's unique position of being an emerging market economy with a diverse workforce, affirmative action policies and an open economy that gives its workforce little protection.

To address these weaknesses and to improve South Arica's overall competitiveness, researchers need to undertake empirical studies. These studies should explain the nature, and confirm the existence, of a relationship between leadership style and organisational climate in South Africa and how it can affect employees' motivation levels, job performance and job satisfaction (Cloete, 2011; Greyvenstein, 1982).

\section{Background to the study}

Researchers have conducted and recorded extensive research on leadership and various organisational outcomes (Haakonsson, Burton, Obel \& Lauridsen, 2008). A number of studies have explored the relationship between leadership and organisational culture (Block, 2003; Mineo, 2009; Ogbonna \& Harris, 2000), leadership and employee engagement (Lockwood, 2008; Stroud, 2009), leadership and organisational performance (Chung \& Lo, 2007; Jing, Avery \& Bergsteiner, 2011; O’Regan, Ghobadian \& Sims, 2005; Rowold, 2011) and leadership and productivity (Kungis, 2006).

A number of studies have explored and investigated the relationship between leadership and climate across the globe (Bishop, 2003; Cloete, 2011; Sawati, Anwar \& Majoka, 2011; Tajasom \& Ahmad, 2011). However, there is still a dearth of empirical studies that explain the nature, and confirm the existence, of a relationship between leadership style and organisational climate in South Africa (Cloete, 2011). This topic is particularly interesting because of South Africa's unique position of being an emerging market economy that a diverse workforce, affirmative action policies and an open economy characterise.

Whilst it is clear that there is a relationship between leadership and various measures of organisational outcomes, only a few studies have provided valuable insights into the relationship between leadership and climate.

For example, Tajasom and Ahmad (2011) explored the effect of leadership style on school climate from the perspective of teachers in Malaysia. A questionnaire assessed transformational and transactional leadership styles. The findings showed that transformational leadership has an effect on four aspects of climate (affiliation, innovation, professional interest and resource adequacy), whilst transactional leadership affected only participatory decisionmaking.

Stroud (2009) investigated the relationship between senior leadership competence and employee engagement in the leaders' organisational units. The study used a Fortune 500 multinational corporation's leadership competency model, along with multi-rater feedback and employee engagement instruments. The results showed that integrity, collaboration and teaming are two definite abilities in senior leaders that seem to have meaningful and positive relationships with employee engagement. However, self-awareness and the ability of senior leaders to adapt, with regard to employee engagement, were not significant. The direct report rater source yielded ability scores that were the best predictors of employee engagement. This highlights the concern that the relationship between senior leadership abilities and employee engagement exists partly because engaged employees gave positive ratings and less engaged employees gave negative ratings of their leaders. However, one must note that bias riddles secondary ability ratings - like situational judgement tests (Silverman, 2000).

Lockwood (2008) conducted a quantitative and descriptive correlation study to examine the relationship between employee self-efficacy, perceived supervisory leadership style and employee engagement in a blue-collar workforce. The results showed a moderately positive relationship between the perceived transformational leadership style of supervisors and employee engagement levels and a moderately negative relationship between a perceived laissez-faire leadership style and subordinate engagement levels.

Haakonsson et al. (2008) conducted an investigation into how misalignments between organisational climate (measured as information-processing demand) and leadership style (measured as information-processing capability) can result in negative performance. They collected the data using a questionnaire. In this research, the key respondent was the chief executive officer (CEO). Therefore, the researchers based their findings on the CEO's perception of climate and leadership style. The research findings showed that misalignments between organisational climate and leadership style are problematic for business performance. If there are misfits, either the organisational climate or the leadership style needs to change. This emphasises the importance of continuously investigating the contribution of organisational climate and the need to understand the role of leadership in creating desired organisational climates.

\section{Trends from the research literature Leadership}

The concept of leadership predates organisations and, according to Wren, Hicks and Price (2004), is as old as civilisation itself. Prophets, priests, kings and chiefs were leaders. Nevertheless, it was not until the 20th century that researchers studied leadership seriously, largely because of the growing number of organisations and the emergence of professional academic disciplines in the social sciences (Wren et al., 2004).

The concept of leadership is complex. A review of the literature highlights the large body of research on leadership and the multitude of definitions of the concept itself (Van 
Niekerk, 2011). Traditional perspectives see leadership as something that creates compliance, respect and cooperation (Anderson, Ford \& Hamilton, 1998). An alternative view is that of Maxwell (1999), who argued that leaders' focus is on investing in people rather than on output from people. This fosters positive relationships that, in turn, improve productivity.

Therefore, the emphasis shifts to the motivation, empowerment and inclusion of followers. Jaques and Clement (1991) defined leadership as a process whereby a person sets direction for others to follow and then takes them in that direction with competence and full commitment. In the contemporary context, leadership is the art of transforming people and organisations in order to effect positive change. Leaders develop respect, appreciation of, and care for, their followers and acknowledge them as powerful sources of knowledge, innovation and performance, all of which are necessary for improving organisations' performance and growth (Oyetunji, 2006)

In the African context, Mbigi (2004) suggested that it is critical to understand the cultural paradigms that influence the way people view leadership. Hampden-Turner and Trompenaars (1997), as Baicher (2005) cited, argued that we can only see what our cultural paradigms allow us to see. This has profound implications for leadership theory and research. A focus on people, their dignity, the collective unit and its brotherhood characterise African leadership. We commonly refer to all of these as ubuntu (Baicher, 2005). African leadership highlights supportiveness, cooperation and solidarity.

One expects the South African cultural paradigm to influence the findings and recommendations of this research. To accommodate the South African cultural paradigm, the authors incorporated the six fundamental values of African leadership in the present study's survey instrument.

For the purpose of this study, leadership is a process in which one person influences a group to achieve a common objective (Northouse, 2001). From this definition, it is clear that leadership occurs within a specific paradigm. The present study adopted a neo-charismatic approach because it has a specific focus on African leadership. This focus is of major importance because the vast majority of employees in South Africa are African. Therefore, organisations should be committed to incorporating African leadership, which requires participation, duty and spiritual authority as well as transparency, accountability and legitimacy (Van der Colff, 2003).

Neo-charismatic theories of leadership, which are relevant to this study, have three similar themes:

1. An emphasis on the symbolic and emotionally appealing behaviours of effective leaders.

2. An explanation of how it is possible for certain leaders to achieve high levels of follower commitment.
3. Less emphasis on theoretical complexity (Robbins, Odendaal \& Roodt, 2009).

There are three theories of neo-charismatic leadership: charismatic, transformational and African. The third is particularly relevant to this study.

Weber initially developed charismatic leadership theory in 1947. House refined it in the 1970s, at approximately the same time as transformational leadership emerged (House \& Aditya, 1997). According to Robbins (1997), charismatic leadership theory is an extension of attribution theory. Charismatic leadership theory postulates that followers attribute heroic or extraordinary leadership abilities to leaders once they have witnessed specific behaviours and they personally acknowledge their leaders. The research on charismatic leadership has predominantly focused on identifying specific behaviours, specifically extremely high confidence, dominance and strong convictions in leaders' beliefs. These differentiate charismatic leaders from noncharismatic ones. There have been several 'charismatic leaders': John F. Kennedy, Martin Luther King Jr, Walt Disney and Steve Jobs (Robbins et al., 2009).

The transformational approach to the study of leadership is concerned with values, ethics, standards and long-term goals (Northouse, 2001). The leader needs to articulate a clearly defined and shared vision to transform an organisation or unit in an organisation and gain the personal commitment of followers to make the achievement of new objectives possible. At the heart of transformational leadership theory is the basic belief that the role of the leader is to energise followers to adopt a new paradigm by appealing to things that are fundamental to their existence (Tosi, Mero \& Rizzo, 2000). Nelson Mandela is an example of a transformational leader who fought for an ideal in which he believed.

The African leadership approach builds on participation, duty and spiritual authority. It requires transparency, accountability and legitimacy (Van der Colff, 2003). Leaders are role models who demonstrate personal commitment to the values and goals their organisations have set. They have the ability to create a compelling vision and achieve the enthusiasm and personal commitment of groups (Baicher, 2005).

African leadership has six fundamental values:

1. respect for the dignity of others

2. group solidarity (an injury to one is an injury to all)

3. team work is greater than the efforts of the individual

4. service to others in the spirit of peace and harmony

5. interdependence and connectedness

6. persuasion (see Mbigi, 2004).

The concept of $u b u n t u$ in African leadership is pivotal because it emphasises the collective brotherhood of humankind. The independence of humanity characterises this concept. It emphasises human dignity and respect and allows for 
consensus, democracy, people mobilisation, solidarity and genuine care (Mbigi, 2004). One criticism of African leadership is that there is still insufficient empirical research to support it (Baicher, 2005). However, the fact remains that this leadership approach has significant relevance for African countries, including South Africa.

This article contributes to our understanding of leadership in the South African context because it uses the individual perceptions of leadership of a sample that comprised $49.3 \%$ African, 26\% white, 19\% Asian and 5\% mixed-race South African respondents.

Note that the annual survey in this particular FMCG organisation embraces all the fundamental values.

\section{Organisational climate}

Although there have been several studies of organisational climate, dating back to the 1960s, a general definition is elusive. Researchers' perspectives orientate their definitions of the concept (Heyart, 2011). For example, some researchers describe organisational climate according to its characteristics. One of the earliest and most commonly accepted definitions (based on citations) of organisational climate (James \& Jones, 1974; Johannesson, 1973; Moran \& Volkwein, 1992; Woodman \& King, 1978) is that of Forehand and Gilmer (1964). They defined it as a set of characteristics that describe an organisation, distinguishes one organisation from another, is relatively stable over time and can influence the behaviour of the organisation's members.

Cooke and Rousseau (1988) distinguished between organisational culture and organisational climate by providing a list of culture and climate definitions. They suggested that climate reflects perceptions of organisational structures and how it feels to be a member of an organisation, whereas beliefs about how to behave are aspects of organisational culture.

Furthermore, organisational culture is the underlying values, beliefs and principles that are the foundation of organisations' management systems. These systems are the management practices and behaviours that reinforce fundamental principles (Denison, 1990). The importance of organisational culture to employees lies in the symbolism, rituals, myths, stories and interpretations that the groups of people, with whom these employees associate and interact, shape (Frost, 1985). Furthermore, Alvesson (2002) states that, when defining what organisational culture is, it is important to emphasise the assumptions and values that underlie social reality.

Castro and Martins (2010) also support the view that one should see culture and climate as different concepts. They claim that organisational culture has deep roots in organisations and uses employees' values, beliefs and assumptions as its basis (Castro \& Martins, 2010). This contrasts with organisational climate, which is a 'snapshot' of a particular time in an organisation that one measures using a range of dimensions (Castro \& Martins, 2010). The dimensions Castro and colleagues (2010) propose are the leadership of immediate managers, transformation and diversity, personal growth and development, interpersonal belonging and fit, general feeling of job satisfaction, employee wellness, image, pay, challenging and interesting work, physical work environment, recognition and acknowledgement. These dimensions generally reflect the dimensions this study uses, specifically those that reflect leadership.

According to Cloete (2011), organisational climate theory suggests that leadership in organisations has a significant effect on determining organisational climate. Organisational climate involves a holistic view of how organisations deal with their employees and environments. Organisations create it using internal factors, which managers largely influence (Ostroff \& Schmitt, 1993). Greyvenstein (1982) conducted a study that found that altering the leadership style in organisations had an effect on organisational climate. This, in turn, affected employees' motivation levels and influenced their job performance and satisfaction. In his research, Goleman (2000) investigated the effect of climate on financial results - like return on sales, revenue growth, efficiency and profitability. Goleman found a direct correlation between the two. He also found that organisations whose leaders used styles, which positively affected climate, had decidedly better financial results than those whose leaders did not.

An increasing number of leaders are recognising that, in their efforts to improve productivity, organisations' competitive advantage lies in their members (Lawler, 2003). The strategic objectives of the FMCG organisation, which is the subject of this study, are growth, productivity, customer service and employee engagement. According to Cloete (2011), the dynamics of service organisations have a direct effect on their clients and on employee performance and attitudes. Each organisation has its own unique characteristics. They include traditions, culture and ways of getting things done, as well as how it treats customers. Although examples vary from one organisation to another, there are similar and identifiable features of organisations' environments that support high-quality customer service. Given that services, by their nature, are intangible, assessing these services often makes it difficult for managers, employees and customers to measure actual service output and quality.

Therefore, organisations' leaders should have insight into their employees' experiences and the environment in which they work to ensure that there is alignment between the required organisational climate and organisational objectives.

Consequently, managers need to conduct regular climate surveys to examine their employees' perceptions of climate and take the necessary measures to correct any misperceptions. Alternatively, they may target organisational areas for improvement, like those the 2012 International Labour Organization Report on global employment trends highlighted, or specific dimensions that Castro and Martins 
(2010) emphasised. This, in turn, requires organisations to devise one or more tests that will systematically observe employees' organisational behaviour. According to Forehand and Gilmer (1964), there are several possible methods of systematically observing this behaviour. The approaches organisations use to assess organisational climate include field studies, measurements of employees' perceptions of organisations, observations of objective organisational properties and experimental variations in organisational properties.

The current study used a perceptual measure of organisational climate and participants played active roles.

\section{Research objective}

A recent study, in a private retail organisation in South Africa, confirmed the existence of a relationship between leadership style and organisational climate (Cloete, 2011). Nevertheless, the authors of the present study decided to examine the relationship between leadership and organisational climate in various industries and across various cultures in South Africa further. To this end, this research study specifically explored this relationship in a South African FMCG organisation.

The research questions that drove this study were:

1. What is the organisational climate in this South African FMCG organisation?

2. What are the main dimensions that affect organisational climate in this South African FMCG organisation?

3. Is there an empirical relationship between leadership and organisational climate in a sample of employees who work for this South African FMCG organisation?

To investigate these questions, the authors followed a quantitative approach with a cross-sectional survey design. They conducted an exploratory factor analysis to investigate the structure of the questionnaire the organisation used. They then grouped the statements into a new set of dimensions.

The authors used Cronbach's alpha to determine the internal reliability of the items in each factor. To test the theoretical model, they applied structural equation modelling (SEM) multivariate analysis to determine and confirm the relationship between the construct of organisational climate and the variable of leadership

\section{The potential value of the study}

Understanding the effect of leadership on organisational climate could improve organisational climate. This, in turn, could lead to improved business and individual performance (Srivastav, 2006). An understanding of the determinants of organisational climate is useful for finding ways of strengthening the organisational climate. Furthermore, this research should build on the existing body of knowledge about leadership and organisational climate in South Africa.

\section{Layout of the article}

The authors explain the research approach and methodology in the section on research design. They then group the findings into the broad themes that emerged from the data: organisational climate and leadership. They discuss these themes in terms of related factors and subthemes.

The article concludes with a discussion of the limitations of the study, implications for business and recommendations for future research.

\section{Research design Research approach}

One can describe the research approach the authors used in this study as a descriptive, cross-sectional field survey, the data as primary data and the data analyses as exploratory and confirmatory.

The respondents completed the questionnaires on paper and placed them in sealed envelopes. They remained anonymous. Once respondents had completed the questionnaires, the questionnaires were then collected, counted and submitted to an external service provider, who captured the data and conducted the initial data analysis. According to Rosnow and Rosenthal (1996), questionnaires are the most appropriate method for collecting large quantities of data that relate to people's perceptions. In fact, the organisation involved in this study used questionnaires annually.

\section{Research method}

To date, studies that have examined organisational climate have primarily been empirical rather than theoretical. This is because organisational climate research uses Lewin's (1951) field theory and social psychology, both of which use quantitative assessment methods like surveys, questionnaires and statistical analysis (Moran \& Volkwein, 1992). In this study, the authors adopted an interactive approach. This approach maintains that individual employees develop shared perceptions of their environment through their interaction with it (Moran \& Volkwein, 1992). The organisational climate provides meaning for employees and allows for a sense of self in a particular environment.

Organisational climate is a conceptually integrated combination of organisational characteristics that one can measure and control (Forehand \& Gilmer, 1964). Schneider (1975) suggested that the focus should shift to a specific climate category. However, the benefit of using generic scales to measure organisational climate is that they are not limited to a specific focus of study. An organisation will be able to identify exactly what areas to focus on and will then be able to determine its own overall climate (Castro \& Martins, 2010). In this study, the organisation had an organisational climate survey that used the specific climate dimensions of leadership and the organisation's needs. 
This section will discuss the sampling, data collection and measurement the authors used to conduct the empirical study.

\section{Research participants}

The target population for this study consisted of all employees in the organisation. The unit of analysis was the individual employee. The total population consisted of 3700 employees. The final sample consisted of 896 employees from all five regions of an FMCG organisation in South Africa, yielding a response rate of $24.2 \%$.

The authors used convenience sampling for this research and participation was voluntary. The target population consisted of professional, management, technical, support, administrative, sales representative and frontline staff (whiteand blue-collar workers), all of whom were permanent employees of this organisation. Therefore, the sample consisted of a rich and diverse representation of employees. Table 1 gives the respondents' demographic details.

The sample consisted of $49.3 \%(n=442)$ African, $26.3 \%$ $(n=236)$ white, $19 \%(n=170)$ Asian and $4.5 \%(n=40)$ mixedrace respondents. The gender split was $63.2 \%(n=566)$ male, $24 \%(n=215)$ female, whilst $12.8 \%(n=115)$ of the respondents did not specify their gender. The authors could not determine a specific reason for this other than the respondents wanted to maintain confidentiality. Most respondents had worked in this organisation for more than ten years $(n=293)$. Only $5 \%$ of the respondents had worked for the organisation for less than one year. Of the respondents, $20.9 \%(n=187)$ had been with the organisation for one to three years, $19.9 \%(n=178)$ for three to five years and $21.1 \%(n=190)$ for five to ten years. Of the sample, the organisation employed $31.6 \%(n=283)$ of the respondents at sales representative or clerical level, $30.2 \%$ $(n=271)$ at middle and junior management level, $24.3 \%$ $(n=218)$ at shop-floor level (like forklift drivers and artisan assistants), $8 \%(n=73)$ at executive and senior management level and $5 \%(n=51)$ at supervisory management level. All respondents were permanent employees of the organisation.

\section{Measuring instrument}

The authors used one measuring instrument to assess both variables. The purpose of the measuring instrument was to assess individual employees' perceptions of several dimensions of organisational climate. The authors included the dimensions of organisational climate, inspirational leadership, work environment and corporate reputation in the original questionnaire.

The original organisational climate questionnaire consisted of two main sections, with 222 items that measured seven dimensions of organisational climate. The focus of section 1 was biographical information. The aim of section 2 was to obtain information about organisational climate. This section covered the main dimensions of inspirational leadership, work environment and corporate reputation. The organisation categorised the dimensions in this way so that the results had
TABLE 1: Respondents' demographic profile.

\begin{tabular}{lll}
\hline Variable & $\boldsymbol{N}$ & $\mathbf{\%}$ \\
\hline Gender & 566 & 63.2 \\
Male & 215 & 24.0 \\
Female & 115 & 12.8 \\
Missing values & & \\
Race & 442 & 49.3 \\
African & 170 & 19.0 \\
Asian & 40 & 4.5 \\
Mixed-race & 236 & 26.3 \\
White & 8 & 0.9 \\
Missing values & & \\
Tenure & 45 & 5.0 \\
0-12 months & 187 & 20.9 \\
1-3 years & 178 & 19.9 \\
3-5 years & 190 & 21.2 \\
5-10 years & 293 & 32.7 \\
More than 10 years & 3 & 0.3 \\
Missing values & & \\
Job level & 73 & 8.1 \\
Executive and senior management & 271 & 30.2 \\
Middle and junior management & 51 & 5.7 \\
Supervisory & 283 & 31.6 \\
Sales representative or clerical & 218 & 24.3 \\
Shop floor & 0 & 0.0 \\
Missing values & & \\
\hline
\end{tabular}

a format that linked to managers' performance areas. The organisation further subdivided the three main dimensions into high performance culture and growth outlook (under the dimension of inspirational leadership); human capital competitiveness; employee relations and organisational health (under the dimensions of work environment); and black economic empowerment and corporate image (under the dimension of corporate reputation).

The questionnaire used a Likert-type scale with five alternative responses for each statement. They ranged from strongly disagree (1) to strongly agree (5), with a central option (3) 'neither agree nor disagree'. The authors scored all the items and obtained the overall score for each dimension by calculating a mean score for each dimension.

Examples of typical items for the main dimensions follow:

\section{Inspirational leadership}

- My goals and objectives are aligned to the business strategy.

- My one-on-ones are useful to me in achieving my goals.

- My immediate manager asks for upward feedback on his or her management style.

\section{Work environment}

- The organisation demonstrates a commitment towards dealing with HIV and/or AIDS in the workplace.

- The organisation provides sufficient assistance for employees who are going through a hard time.

- The organisation takes occupational health and safety seriously.

\section{Corporate reputation}

- The organisation has good company values.

- People in my team live the organisational values. 
- It is clear to me that helping to uphold the organisation's corporate reputation is my responsibility.

\section{Research procedure}

The authors obtained permission to conduct the research in the organisation and across all regions from the business director concerned. They administered the questionnaire to all employees during the FMCG organisation's annual climate survey. They collected the data over a period of one month by distributing online questionnaires to the various regional human resources departments.

A representative from the human resources department facilitated the employee sessions. The role of the human resources representative was to clarify any uncertainties about biographical groupings, to explain terminology, to ensure that employees completed the questionnaires individually and to ensure confidentiality.

To ensure that all employees had an equal opportunity to complete these questionnaires, the authors made the questionnaires available to every employee on the morning, afternoon and night shifts for a period of one month. Each employee received a questionnaire, an envelope and a confidentiality sticker.

Once the employees had completed the questionnaire, the employees placed them in the envelopes, sealed the envelopes and signed the register to indicate that they had completed it.

Participation in the study was voluntary and respondents received assurances that their responses would remain confidential and anonymous. Because this is an annual process, the respondents received no offers of incentives. The human resources representative then submitted all the sealed envelopes to the external organisation that recorded and analysed the data.

\section{Data analysis}

SPSS version 20, AMOS version 20 statistical program (2011) completed the statistical analyses.

\section{Results}

\section{Inspirational leadership and organisational climate}

For the purposes of this study, the authors referred to the construct of leadership as 'inspirational leadership' and aligned it to the statements that referred to this construct. They measured the climate of the organisation by using the organisational climate questionnaire. To determine factorability and sampling adequacy, they conducted the Kaiser-Meyer-Olkin measure of sampling adequacy and Bartlett's test of sphericity.

Table 2 displays the results. Both indicators yielded adequate scores. According to Hair, Anderson, Tatham and
Black (1995), a measure of 0.90 or above for sample adequacy is very good, whereas the Bartlett test of sphericity indicates significant correlations between the variables.

The authors conducted an exploratory factor analysis (EFA) to investigate the questionnaire's underlying factor structure. They conducted a principal component analysis using the varimax rotation approach. They used a cut-off point of 0.4 to include loadings and consider them as important, as Hair et al. (1995) indicated.

The Kaiser criterion specifies that factors with eigenvalues of 1.00 or more indicate distinct factors and that one can retain them.

The authors used the scree test to determine the number of factors to extract. The Kaiser criterion showed that they could extract nine factors. This explained $65.18 \%$ of the total variance based on the cumulative percentage of eigenvalues.

After investigating the new factor structure and statements, the authors named the dimensions as performance management; self-management practices; innovation and empowerment; employee relations; senior leadership behaviour; diversity; black economic empowerment; corporate image and governance; and organisational support (see Table 3).

These dimensions largely reflect the typical dimensions previous organisational climate studies measured: leadership; job performance; job satisfaction; transformation and diversity; personal growth and development; image; pay; challenging and interesting work; physical work environment; and recognition and acknowledgement (Castro \& Martins, 2010; Cloete, 2011).

Table 4 gives descriptive statistics (with specific reference to means and standard deviations). It also gives the Cronbach's alpha coefficients for the various organisational climate dimensions and the independent variable of inspirational leadership. The alpha coefficients of the nine climate dimensions range from 0.86-0.97. All the alpha coefficients were acceptably high, with the exception of inspirational leadership (0.72), which was just above the cut-off that Nunnally (1978) recommended. Nevertheless, the authors considered that the alpha coefficients of all ten dimensions (nine climate dimensions and leadership) had adequate internal consistency reliabilities because they were above the recommended minimum cut-off of 0.70 (Nunnally, 1978).

The authors determined the climate score for the organisation by aggregating the individual scores of

TABLE 2: The Kaiser-Meyer-Olkin measure and Bartlett's test.

\begin{tabular}{ll}
\hline Kaiser-Meyer-Olkin measure of sampling adequacy & $\mathbf{0 . 9 8 7}$ \\
\hline Approximate chi-square & 101106.147 \\
Bartlett's test of sphericity & - \\
$d f$ & 5671 \\
Significance & 0.000 \\
\hline
\end{tabular}

$d f$, degrees of freedom. 
employees. This is consistent with the guidelines of Denison, Janovics, Young, and Cho, 2006), who suggested that homogeneous individual scores indicate the shared organisational characteristic of organisational climate. From Table 4, it is clear that one can describe the climate dimension of the organisation as positive, given that the overall mean score for all dimensions measured above 3.2. According to Odendaal (1997), where one uses a scale of 1 to 5 (strongly disagree to strongly agree), the suggested cut-off point is 3.2. Research that the Human Sciences Research Council (HSRC) conducted supports this. It proposes that an average of 3.2 is a good guideline for differentiating between positive and negative perceptions (see Castro \& Martins, 2010).

Although positive, employees rated the dimensions of black economic empowerment (3.98) and diversity (3.97) the lowest. The reasons for this could be, firstly, that at highly skilled levels, workers from previously disadvantaged backgrounds accounted for only half of the organisation's employees. Secondly, a further breakdown showed that Africans occupy only $29.3 \%$ of junior to executive management positions in the organisation. Therefore, one could regard these two dimensions as areas that require attention in this particular organisation.

The authors measured the behaviour of the organisation's leaders, as far as leadership is concerned, by asking questions about the behaviour of an employee's leader. The results show that employees were satisfied with the inspirational leadership (4.26), and the associated behaviour, that their leaders demonstrated.

\section{Structural equation modelling results}

The authors applied the SEM multivariate analysis technique to confirm the factor analysis results and to determine the relationship between the construct of organisational climate and the variable of inspirational leadership. Except for a statistical significance index (chi square), SEM uses several global fit indices to determine model fit.

There is no consensus on which goodness of fit indices one should use to judge the adequacy of a model. However, there is agreement that SEM has no single statistical test that best describes the strength of a model's prediction. Therefore, this means that one should consider more than one (Hu \& Bentler, 1998; Milsap, 2002). The authors originally tested two models using the covariance matrix based on SEM procedures. They tested alternative models based on the theory. They made changes to the models according to the modification indices.

\section{Model 1: Leadership and organisational climate}

Firstly, the authors tested model 1 with leadership and organisational climate as separate constructs. The results yielded the following default model scores (see Table 5).

The results also showed that the covariance matrix is not a positive definite. According to Schumacker and Lomax (2004), non-positive definite covariance matrices occur when the determinant of the matrix is zero or when the inverse of the matrix is not possible. Correlations greater than 1.0, linear dependence amongst observed variables, colinearity amongst the observed variables or a variable that is a linear combination of other variables can cause this. A further investigation of the two constructs indicated that, in a number of instances, the authors used the same variables in different dimensions.

\section{Model 2: Inspirational leadership and organisational climate}

In model 2, one shows the relationship between leadership and organisational climate by applying the Goodness-of-Fit

TABLE 3: Dimensions of organisational climate.

\begin{tabular}{ll}
\hline Dimension & Description \\
\hline $\begin{array}{l}\text { Performance management } \\
\text { Self-management practices }\end{array}$ & Refers to the practices, policies and procedures organisations use to manage employee performance \\
$\begin{array}{l}\text { Innovation and empowerment } \\
\text { Employee relations }\end{array}$ & Refers to the practices and behaviours employees adopt when doing their work \\
Senior leadership behaviour & Refers to the quality of the relationship between the employees and managers \\
\hline $\begin{array}{l}\text { Diversity } \\
\text { Black economic empowerment }\end{array}$ & $\begin{array}{l}\text { Reod of the organisation } \\
\text { gorporate leaders in the organisation to lead employees in the right direction and to make the right decisions for the }\end{array}$ \\
Organisational support & Refers to the promotion and advancement of black, mixed-race and Asian employees in the organisation \\
\hline
\end{tabular}

TABLE 4: The means, standard deviations and Cronbach's alphas for the dimensions of organisational climate and inspirational leadership.

\begin{tabular}{|c|c|c|c|c|c|}
\hline Dimension & $N$ & M & SD & Cronbach's alpha & Number of items \\
\hline Inspirational leadership & 896 & 4.26 & 12.09 & 0.72 & 20 \\
\hline Organisational support & 896 & 4.22 & 14.45 & 0.97 & 18 \\
\hline Corporate image and governance & 896 & 4.37 & 8.08 & 0.96 & 14 \\
\hline Black economic empowerment & 896 & 3.98 & 5.69 & 0.94 & 7 \\
\hline Diversity & 896 & 3.97 & 4.95 & 0.92 & 6 \\
\hline Senior leadership behaviour & 896 & 4.09 & 4.77 & 0.95 & 6 \\
\hline Employee relations & 896 & 4.03 & 4.60 & 0.90 & 6 \\
\hline Innovation and empowerment & 896 & 4.17 & 4.36 & 0.91 & 8 \\
\hline Self-management practices & 896 & 4.35 & 3.48 & 0.91 & 6 \\
\hline Performance management & 896 & 4.07 & 3.23 & 0.86 & 4 \\
\hline
\end{tabular}

M, mean; SD, standard deviation. 
(GFI) measures for non-nested models. GFI tests determine whether one should accept or reject the model that one is testing. If one accepts the model, one can interpret the coefficients (Garson, 2004).

According to Schumacker and Lomax (2004), GFI measures with a value of 0.90 or higher show acceptable fit. The proposed model is a non-nested model, which means that one of the models does not derive from the other simply by restricting parameters. Non-nested models are a combination of two unrelated factors. When models are not nested, one cannot use the chi-square test. Instead, one must use other model comparison methods (like the Akaike's Information Criterion (AIC) or the Expected Cross-Validation Index (ECVI). Indeed, Kline (1998) writes, 'The chi-square statistic can be used as a test of significance only for hierarchical [nested] models.'

Therefore, the authors used the GFI statistic that Jöreskog and Sorbom (1993) created as an alternative to the chi-square test in this research. It calculates the proportion of variance that the estimated population covariance accounts for (Tabachnick \& Fidell, 2007). According to Diamantopoulos and Siguaw (2000), smaller values for the AIC and consistent AIC (CAIC) suggest a good fit. However, for a parsimonious model, because these indices are not normed to a $0-1$ scale, it is difficult to suggest a cut-off, except to suggest that the model that produces the lowest value will be the best model to use.

For model 2, the authors reported the GFI test with the AIC; Bays Information Criteria (BCC); Bayesian Information Criterion (BIC) and CAIC as alternative measures for nonnested models; and the baseline fit measures of the normed fit index (NFI); relative fit index (RFI); the incremental fit index (IFI); Tucker-Lewis index (TLI); and the comparative fit index (CFI). A value of 0.90 or above indicates a good model fit (Hu \& Bentler, 1998) for the mentioned baseline fit measures. To overcome the problem of sample size, Browne and Cudeck (1993) suggested that the root square error of approximation (RMSEA), with values ranging from 0.05 to 0.08 , is a 'good fit'.

The results of the AIC, BCC, BIC and CAIC scores showed major improvements for model 2 (Table 6). The scores of all four indices were smaller than was the case for model 1 . The smaller scores indicated a relatively better fit and that model
2 is the better model for comparison. This is an indication that the parameters 'cross validate' well in a sample of the same size.

Model 2 (see Figure 1) confirmed the positive relationship of 0.88 between inspirational leadership and organisational climate.

The GFI is 0.841 , which is a slightly inadequate fit. The GFI ranges from $0-1$, and should be equal to or greater than 0.9 (Schumacker \& Lomax, 2004).

The NFI was 0.927, the RFI was 0.906, the IFI was 0.930, the TLI was 0.910 and the CFI was 0.930 . These results show adequate fit because all these values are close to the recommended perfect fit, where 0 shows 'no fit' and 1 shows 'perfect fit' (Schumacker \& Lomax, 2004).

The RMSEA for this model was high at 0.149 for the default model and 0.496 for the independence model. One cannot compute the saturated model using RMSEA. Therefore, the authors omitted it from this statistical analysis. They used the same argument for not computing the root mean square residual (RMR). As the authors indicated earlier, they used alternative incremental fit indices for studying the proposed non-nested model.

Table 8 shows high levels of correlation between inspirational leadership and the climate dimensions. This explains between $65.3 \%$ and $87.7 \%$ of the variance.

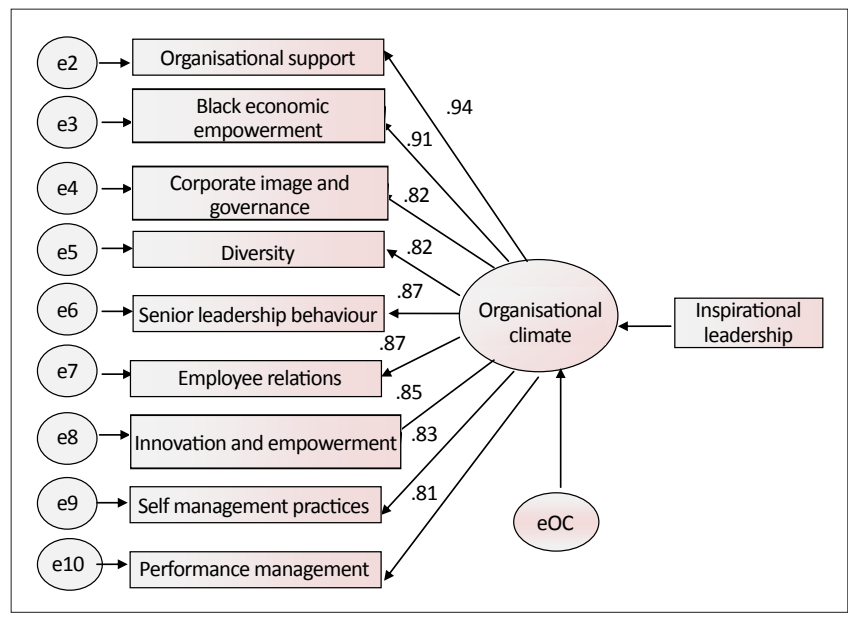

FIGURE 1: Relationship between inspirational leadership and organisationa climate.

TABLE 5: Results of fit indices for model 1.

\begin{tabular}{llll}
\hline Model 1 & AIC & BCC & BIC \\
\hline Default model & 537140.00 .123 & 537150.00 .906 & 539010.00 .243 \\
\hline
\end{tabular}

AIC, Akaike's Information Criterion; BCC, Bays Information Criteria; BIC, Bayesian Information Criterion; CAIC, consistent Akaike's Information Criterion.

TABLE 6: Results of fit indexes for model 2 .

\begin{tabular}{lllll}
\hline Model 2 & AIC & BCC & BIC & CAIC \\
\hline Default model & 7660.976 & 7670.473 & 8620.935 & 8820.935 \\
Saturated model & 1100.000 & 1110.369 & 3730.887 & 4280.887 \\
Independence model & 99790.817 & 99800.066 & 100270.796 & 100370.796 \\
\hline
\end{tabular}

AIC, Akaike's Information Criterion; BCC, Bays Information Criteria; BIC, Bayesian Information Criterion; CAIC, consistent Akaike's Information Criterion. 
TABLE 7: Squared multiple correlations (organisational climate relationship).

\begin{tabular}{ll}
\hline Dimension & Estimate \\
\hline Inspirational leadership & 0.770 \\
Performance management & 0.653 \\
Self-management practices & 0.689 \\
Innovation and empowerment & 0.715 \\
Employee relations & 0.756 \\
Senior leadership behaviour & 0.755 \\
Diversity & 0.667 \\
Black economic empowerment & 0.673 \\
Corporate image and governance & 0.822 \\
Organisational support & 0.877 \\
\hline
\end{tabular}

TABLE 8: Standardised regression weights: organisational climate.

\begin{tabular}{lll}
\hline Dimension & Main constructs & Estimate \\
\hline Organisational climate & $<--$ Inspirational leadership & 0.877 \\
Organisational support & $<--$ Organisational climate & 0.937 \\
Corporate image and governance & $<---$ Organisational climate & 0.907 \\
Black economic empowerment & $<---$ Organisational climate & 0.820 \\
Diversity & $<---$ Organisational climate & 0.817 \\
Senior leadership behaviour & $<---$ Organisational climate & 0.869 \\
Employee relations & $<---$ Organisational climate & 0.870 \\
Innovation and empowerment & $<---$ Organisational climate & 0.845 \\
Self-management practices & $<---$ Organisational climate & 0.830 \\
Performance management & $<---$ Organisational climate & 0.808 \\
\hline
\end{tabular}

In Figure 1, the arrows show a direct structural relationship. The figures above these arrows show the effect of the variable on the dimensions. The figures above the dimensions show the variance that this dimension on the variable explained.

The regression coefficients show a structural relationship between inspirational leadership and organisational climate. Table 7 and Figure 1 show that the variable of inspirational leadership (0.77) had an effect on the variable of organisational climate and explained $77 \%$ of the variance. Furthermore, the results in Figure 1 show that performance management was the weakest indicator of organisational climate, with a variance of $65 \%$, followed by diversity and black economic empowerment. Both had low indicators of $82 \%$ and a variance of 0.67 . Organisational support ( 0.88 variance) and corporate image and governance (0.82 variance) were the strongest indicators of organisational climate. Their effect is also the highest with scores of $94 \%$ and $91 \%$, respectively. Senior leadership, employee relations, innovation and empowerment and self-management practices all show strong indicators of $81 \%$ and higher.

The regression model is part of the SEM process and confirms the relationships between the various dimensions. Table 8 gives the SEM regression analysis results. They show the structural relationships.

The results suggest that there is a structural relationship between inspirational leadership and organisational climate.

\section{Discussion}

The main aim of this study was to explore the relationship between leadership and organisational climate.

\section{Summary of the findings}

The results of the study suggested that one could describe the overall organisational climate of the FMCG organisation as very positive with a mean of 4.14 (the cut-off score was 3.2). The results also showed a strong positive relationship between inspirational leadership and organisational climate (0.88). These results are consistent with previous studies, which investigated the relationships between various leadership styles and organisational climate (Cloete, 2011; Goleman, 2000).

The authors grouped the statements into dimensions and developed a model that shows nine dimensions of organisational climate based on the organisational climate questionnaire. They conducted a SEM multivariate analysis to determine the relationship between the various organisational climate dimensions.

The results showed a positive relationship between organisational climate and each of the nine dimensions. As far as the second aim of this research was concerned, the authors identified the main dimensions that affect organisational climate: organisational support, corporate image and governance have the greatest effect on organisational climate. Although all indicators were high, the indicators of organisational climate of performance management, followed by black economic empowerment and diversity were lower.

This is consistent with research findings on the challenges that face South African business leaders, in which black economic empowerment, cultural and workforce diversity were amongst the main challenges (Baicher, 2005). Similarly, research that Botha and Claassens (2010) conducted concluded that South African organisations have to contend with unique issues relating to cultural diversity. Botha and Claassens (2010) also suggested that leadership programmes should place more emphasis on African leadership abilities to address the needs of South African society. However, it is important to emphasise that researchers need to conduct more research in order to understand how African leadership abilities will be able to overcome certain macro-environmental constraints, like lack of education, low socioeconomic status, slow economic growth as well as the issues of black economic empowerment and diversity.

A possible explanation for why performance management, black economic empowerment and diversity indicators yielded lower results is the racial composition of the sample in the present research. The sample consisted of $49.3 \%$ African, 19\% white, 19\% Asian and 5\% mixed-race South African respondents. Therefore, it does not reflect the demographics of the South African population and the full cultural spread of perceptions of African leadership. This could explain the lowest ranked dimensions the authors identified: perceptions of performance management, black economic empowerment and diversity. As the authors have mentioned earlier, highly skilled workers and workers from 
previously disadvantaged backgrounds currently account for only half of the organisation's employees, whilst Africans account for only $29.3 \%$ of junior to executive management positions. This tendency is similar to that the Commission of Employment Equity (CEE) (2011-2012) reported. This shows that transformation in organisations is happening very slowly. The fact that white males still dominate at the various management levels in the present sample illustrates this.

\section{Managerial implications}

Given the existence of a relationship between leadership and organisational climate, the authors propose that the organisation's leaders should change their practices to achieve even higher levels of positive organisational climate. In South Africa, business leaders face several generic and unique challenges, like globalisation, diversity, the need for black economic empowerment and transformation. Industrial or organisational psychologists could support the process through specific leadership interventions, including executive coaching programmes and behavioural assessments, followed by leadership effectiveness training. Furthermore, to address diversity, the leadership programmes of South African organisations need to emphasise African leadership abilities more (Botha \& Claassens, 2010). Organisations have been attempting to redress past discrimination in line with the employment equity (EE) strategies as the legal framework specifies.

Despite these efforts, national statistics have shown that demographic changes to make employees from previously disadvantaged backgrounds more representative in the workplace remains slow (Commission of Employment Equity Annual Report, 2011-2012). The organisation in the present study has already spent large amounts of money on transformation and developing previously disadvantaged workers, more especially Africans. However, it seems that it will take time for the effects of this expenditure to be visible at all levels and for the organisation to be able to portray 'African leadership' based on the six fundamental values of African leadership.

The authors anticipate that, as greater changes with regard to transformation occur, this will allow the organisation to align its value systems to those of most of its employees and of the country. This could improve its organisational climate further. These values would include interconnectedness, collectivism, solidarity, dignity and respect. The organisation could use teams and autonomous work groups to promote collectivism and solidarity. This form of work could change the way in which it addresses critical business issues, like decision-making and developing employee abilities (Botha \& Claassens, 2010).

The performance management practices, policies and procedures the organisation uses to manage employee performance, which take into account organisational goals, could create a sense of interconnectedness between employees.
Building and maintaining quality relationships between employees and managers would improve organisational climate further. The organisation could achieve this as part of the talent management process of engaging, developing and managing employees. In regular, one-on-one discussions between managers and their employees, the organisation could create a platform to raise and address challenges, brainstorm approaches and address the needs of both.

These recommendations are valuable to the organisation that participated in this research and have implications for other South African organisations because 'African leadership' is necessary to improve organisational climate and its dimensions. This would address the whole list of outcomes unpacked in the global competitiveness report.

\section{Limitations and recommendations}

Because the authors conducted the study in only one FMCG organisation, obviously one cannot generalise the results to all organisations in South Africa.

The study explored individual employees' perceptions of various dimensions of organisational climate, including leadership. However, the authors found it difficult to draw definite parallels with the results of previous studies that investigated leadership and organisational climate through leadership style questionnaires that measure various leadership styles.

The authors developed the questionnaire specifically for the FMCG organisation in which they conducted the study. Therefore, it may not be suitable for other organisations. However, the organisation can now use the validated climate questionnaire and model with much more confidence in future surveys and to initiate change.

The recommendation for future research is that samples should include employees from various industries in South Africa. The use of a measuring instrument, which includes assessing a variety of leadership styles, would improve the quality of future research and recommendations.

\section{Conclusion}

Despite some limitations the findings emphasised the importance of certain generic and specific leadership practices for creating the desired organisational climate in South Africa and in the FMCG environment. The recommendations are not only valuable to the organisation that participated in this research but have implications for other South African organisations because 'African leadership' is necessary to improve organisational climate and its dimensions.

\section{Acknowledgments Competing interests}

The authors declare that they have no financial or personal relationship(s) that may have inappropriately influenced them when they wrote this article. 


\section{Authors' contributions}

N.M. (University of South Africa) promoted A.E. (University of South Africa) for her master's dissertation. The article originated from her research work. N.M. gave advice on literature content, on the research methodology and on interpreting the research results. A.E. contributed to the statistical analysis, interpretation of the results and recommendations.

\section{References}

Alvesson, M. (2002). Understanding organizational culture. London: Sage.

Anderson, T.D., Ford, R., \& Hamilton, M. (1998). Transforming leadership: Equipping yourself and coaching others to build a leadership organisation. (6th edn.). London: St Lucie.

Baicher, R. (2005). Leadership competencies of successful business leaders in South Africa. Master's dissertation. Pretoria: University of South Africa.

Bishop, D. (2003). The relationship between faculty perceptions of music unit administrators' leadership behaviour and organizational climate. Doctoral thesis. Oxford: University of Mississippi.

Block, L. (2003). The leadership-culture connection: An exploratory investigation Leadership and Organization Development Journal, 24(5), 318-334. http://dx.doi. org/10.1108/01437730310494293

Botha, S., \& Claassens, M. (2010). Leadership competencies: The contribution of the Bachelor in Management and Leadership (BML) to the development of Leaders at First National Bank, South Africa. International Business and Economics Research Journal, 9(10), 77-87.

Browne, M.W. \& Cudeck, R. (1993). Alternative ways of assessing model fit. In K.A. Bollen\& J.S. Long, (Eds.) Testing Structural Equation Models, 136-162. Beverly Hills, CA: Sage

Castro, M., \& Martins, N. (2010).The relationship between organisational climate and employee satisfaction in a South African information and technological organisation. South African Journal of Industrial Psychology, 36(1), 1-9.

Commission of Employment Equity Annual Report 2011-2012, Department of Labour. Retrieved January 25, 2014, from https://www.labour.gov.za/downloads/ documents/annual-reports/employment-equity/2011-2012/12th\%20CEE\%20 Report.2012.pdf

Cooke, R., \& Rousseau, D. (1988). Behavioural norms and expectations. A quantitative approach to the assessment of organizational culture. Group and Organization Studies, 13(3), 245-273. http://dx.doi.org/10.1177/105960118801300302

Chatman, J. (1989). Improving international organizational research: A model of person-organization fit. Academy of Management Review, 14(3), 333-349. http:// person-organization fit. Academy of Man
dx.doi.org/10.5465/AMR.1989.4279063

Chung, R., \& Lo, C. (2007). The relationship between leadership behaviour and organizational performance in non-profit organizations, using social welfare charity foundations as an example. Journal of American Academy of Business, 12(1), 83-87.

Cloete, M. (2011). The relationship between leadership styles and organisational climate. Master's dissertation. Pretoria: University of South Africa.

Denison, D.R. (1990). Corporate culture and organizational effectiveness. New York: Wiley.

Denison, D.R., Janovics, J., Young, J., \& Cho, H.J. (2006). Diagnosing organizational cultures: Validating a model and method. Working Paper, Denison Consulting Group Retrieved August 19, 2013, from http://www.denisonconsulting.com/ resources/ResourcesbyTopic/CultureAndPerformanceResources.aspx.

Diamantopoulos, A., \& Siguaw, J.A. (2000). Introducing LISREL. London: Sage. PMCid:PMC1298088

Forehand, G.A., \& Gilmer, B. v H. (1964). Environmental variation in studies of organizational behaviour. Psychological Bulletin, 62(6), 361-380. http://dx.doi. org/10.1037/h0045960, PMid:14242590

Frost, P.J. (1985). Organizational culture. Newbury Park: Sage.

Garson, G.D. (2004). Structural equation modeling. Retrieved November 20, 2012 from http://www2.uta.edu/sswmindel/S6367/SEM/Principles\%20of\%20SEM.pdf

Gerzon, M. (2006). Leading through conflict: how successful leaders transform differences into opportunities. Boston: Harvard.

Goleman, D. (2000). Leadership that gets results. Harvard Business Review, 78(2), 78-91.

Greyvenstein, L.C.J. (1982). The role of the chief executive officer in generating organisational climate in a South African banking organisation. Master's dissertation. Pretoria: University of South Africa.

Hampden-Turner, C. \& Trompenaars, F. (1997). Riding the waves of culture: understanding cultural diversity in business. Nicholas Brealey, London.

Haakonsson, D.D, Burton, R.M., Obel, B., \& Lauridsen, J. (2008). How failure to align organizational climate and leadership style affects performance. Management Decision, 46(3), 406-432. http://dx.doi.org/10.1108/00251740810863861

Hair, J.F. Jr., Anderson, R.E, Tatham, R.L., \& Black, W.C. (1995). Multivariate data analysis with readings. (4th edn.). Engelwood Cliffs, New Jersey.
Harris, I.H. (2001). Examining the relationship between emotional intelligence competencies in NCAA division, athletic directors and the organisational climates competencies in NCAA division, athletic directors and the organisational
within their departments. Doctoral thesis. Ames: lowa State University.

Heyart, B. (2011). The role of organizational climate and culture in service encounters. Doctoral thesis. Detroit: Wayne State University.

House, R.J., \& Adjitya, R.N. (1997). The social scientific study of leadership: Quo vadis? Journal of Management, 23(3), 409-474. http://dx.doi. org/10.1177/014920639702300306

Hu, L.T., \& Bentler, P.M. (1998). Cut-off criteria for fit indexes in covariance structure analysis: Conventional criteria versus new alternatives. Structural Equation Modelling: A Multidisciplinary Journal, 6, 1-55.

International Labour Organization (ILO) (n.d.). Retrieved September 20, 2012, from http://www.ilo.org/global/research/global-reports/global-employment-trends/ lang--en/index.htm.

James, L.R., \& Jones, A.P. (1974). Organizational climate: A review of theory and research. Psychological Bulletin, 81(12), 1096-1112. http://dx.doi.org/10.1037/ h0037511

Jaques, S., \& Clement, S. (1991). Executive leadership: A practical guide to managing complexity. Cambridge, MA: Blackwell. PMCid:PMC1519489

Jing, F.F., Avery, G.C., \& Bergsteiner, H. (2011). Organizational climate and performance in retail pharmacies. Leadership and Organization Development Journal, 32(3), 224-242. http://dx.doi.org/10.1108/01437731111123898

Johannesson, R.R. (1973). Some problems in the measurement of organizational climate. Organizational Behavior and Human Performance, 10(1), 118-114. http://dx.doi.org/10.1016/0030-5073(73)90008-1

Jöreskog, K., \& Sörbom, D. (1993), LISREL 8: Structural equation modeling with the simplis command language. Chicago, IL: Scientific Software International Inc.

Kinicki, A., \& Fugate, M. (2012). Organizational behavior: Key concepts, skills and best practices. (5th edn.). New York: McGraw-Hill/Irwin.

Kline, R.B. (1998). Principals and practices of structural equation modeling. The Guilord Press. NY.

Kungis, J.P. (2006). Leadership and productivity: A study of the perceptions of the non-supervisory civilian personnel at the garrison. Doctoral thesis. Minneapolis: non-supervisory civili
Capella University.

Lawler, E.E. (2003). Treat people right. San Francisco: Jossey-Bass.

Lewin, K. (1951). Field theory in the social sciences. New York: Harper.

Lindbeck, R. (2004). A study of the relationship between leadership styles and organizational climate and the impact of organizational climate on business results. Doctoral thesis. Malibu: Pepperdine University.

Lockwood, M.A. (2008). The relationship of self-efficacy, perceptions of supervisor leadership styles and blue-collar employee engagement. Doctoral thesis. Phoenix: University of Phoenix.

Maxwell, J.C. (1999). The 21 indispensable qualities of a leader: Becoming the person others will want to follow. Nashville, TN: Thomas Nelson.

Mbigi, L. (2004). Leadership: In search of an African spirit. Business in Africa, 38-41.

Milsap, R.E. (2002). Structural equation modeling: A user's guide. In F. Drasgow, $\& N$. Schmitt (Eds.), Measuring and analyzing behavior in organizations (pp 257-301). San Francisco: Jossey-Bass.

Mineo, F.P. (2009). An examination of the relationship between leadership styles and organizational sector culture for the emergency medical services leader. Doctoral thesis. Minneapolis: Capella University.

Moran, E.T., \& Volkwein, J.F. (1992). The cultural approach to the formation of organizational climate. Human Relations, 45, 19-47. http://dx.doi. org/10.1177/001872679204500102

Munsamy, S. (2007). An investigation into the leadership development strategy implemented by a manufacturing organization in South Africa. Master's dissertation. Pretoria: University of South Africa.

Myeni, A. (2010). Leadership behaviour and employee morale within the department of agriculture. Doctoral thesis. Pretoria: University of South Africa.

Northouse, P.G. (2001). Leadership: theory and practice. Thousand Oaks, CA: Sage.

Nunnally, J.C. (1978). Psychometric theory. (2nd edn.). New York: McGraw-Hill.

Odendaal, A. (1997). Deelnemende bestuur en korporatiewe kultuur: Onafhanklike konstrukte? [Participative management and corporate culture: Independent constructs?]. Master's dissertation. Johannesburg: Rand Afrikaans University.

Ogbonna, E., \& Harris, L.C. (2000). Leadership style, organizational culture and performance: Empirical evidence from UK companies. International
Journal of Human Resource Management, 11(4), 766-788. http://dx.doi. Journal of Human Resource M
org/10.1080/09585190050075114

O'Regan, N., Ghobadian, A., \& Sims, M. (2005). The link between leadership, strategy and performance in manufacturing SMEs. Journal of Small Business Strategy, 15(2), 45-57.

Ostroff, C., \& Schmitt, N. (1993). Configurations of organisational effectiveness and efficiency. Academy of Management Journal, 36(6), 1345-1357. http://dx.doi. org $/ 10.2307 / 256814$

Oyetunji, C.O. (2006). The relationship between leadership style and school climate in Botswana secondary schools. Doctoral thesis. Pretoria: University of South Africa.

Robbins, S.P. (1997). Organizational Behavior. (8th edn.). Upper Saddle River: Prentice-Hall Inc.

Robbins, S.P., Odendaal, A., \& Roodt, G. (2009). Organisational behaviour: Global and South African perspectives. (2nd edn.). Cape Town: Pearson. 
Rosnow, R.L., \& Rosenthal, R. (1996). Beginning behavioral research: A conceptual primer. (2nd edn.). Englewood Cliffs, NJ: Prentice-Hall.

Rowold, J. (2011). Relationship between leadership behaviours and performance: The moderating role of a work team's level of age, gender and cultural hetrogeneity. Leadership and Development Journal, 32(6), 628-647. http:// dx.doi.org/10.1108/01437731111161094

Sawati, M., Anwar, S., \& Majoka, M.I. (2011). Principals' leadership styles and their impact on schools' academic performance at secondary level in Khyber Pakhtoonkhwa, Pakistan. Interdisciplinary Journal of Contemporary Research in Business, 3(1), 1038-1046.

Schneider, B. (1975). Organizational climates: An essay. Personnel Psychology, 28(4), 447-479. http://dx.doi.org/10.1111/j.1744-6570.1975.tb01386.x

Schumacker, R.E., \& Lomax, R.G. (2004). A beginner's guide to structural equation modelling. (2nd edn.). Mahwah, NJ: Lawrence Erlbaum.

Silverman (2000). Doing qualitative research: A practical handbook. University of Michigan: Sage.

Srivastav, A.K. (2006). Organizational climate as a dependent variable: Relationship with role stress, coping strategy and personal variables. Journal of Management Research, 6(3), 125-135.
Stroud, R.N. (2009). The relationship between leadership competence and employee engagement. Doctoral thesis. Neptune City: Graduate School of Applied and Professional Psychology.

Tabachnick, B.G. \& Fidell, L.S. (2007), Using Multivariate Statistics. (5th edn.). New York: Allyn and Bacon. PMCid:PMC2724990

Tajasom, A., \& Ahmad, Z. (2011). Principals' leadership style and school climate: Teachers' perspective. The International Journal of Leadership in Public Services, 7(4), 314-327. http://dx.doi.org/10.1108/17479881111194198

Tosi, H.L., Mero, N.P., \& Rizzo, J.R. (2000). Managing organizational behavior. Cambridge, MA: Blackwell.

Van der Colff, L. (2003). Leadership lessons from the African Tree. Leadership and Organisational Development Journal, 41(3), 257-261.

Van Niekerk, A. (2011). The impact of senior management on middle management's experience of integrity. Master's dissertation. Pretoria: University of South Africa.

Woodman, R.W., \& King, D.C. (1978). Organizational climate: Science or folklore? Academy of Management Review, 3(4), 816-826. http://dx.doi. org/10.2307/257936

Wren, J.T., Hicks, D.A., \& Price, T.L. (2004). Modern classics on leadership. Cheltenham Blackwell. 